\title{
Renal-hepatic-pancreatic dysplasia: an autosomal recessive malformation
}

\author{
R Torra, L Alós, J Ramos, X Estivill
}

\begin{abstract}
We report two brothers with a cystic malformation of the kidneys, liver, and pancreas. In both cases the malformation was fatal and the children died shortly after birth. The pathological findings, consisting of multicystic dysplastic kidneys, dilated and dysgenetic bile ducts, dilated pancreatic ducts, and polysplenia, correspond to those reported by Ivemark as renal-hepatic-pancreatic dysplasia. Many polymalformation syndromes include cystic affectation of these three organs, so this syndrome could be an isolated entity or a final common pathway of response of these organs to a variety of developmental disturbances, which could also include splenic abnormalities. We propose an autosomal recessive pattern of inheritance for renal-hepatic-pancreatic dysplasia. ( $($ Med Genet 1996;33:409-412)
\end{abstract}

Key words: renal-hepatic-pancreatic-dysplasia; autosomal recessive disorder; dysplastic kidneys.

Service of Genetics, Centre for Medical Genetics, Hospital Clínic, Villarroel 170, 08036 Barcelona, Catalunya, Spain $\mathrm{R}$ Torra

$\mathrm{X}$ Estivill

Service of Nephrology, Hospital Clínic, Villarroel 170, 08036 Barcelona Catalunya, Spain $\mathrm{R}$ Torra

Service of Pathology, Hospital Clínic, Villarroel 170, 08036 Barcelona, Catalunya, Spain L Alós

Service of Pathology, Hospital Virgen de la Arrixaca, Murcia

Spain

J Ramos

Correspondence to: Dr Torra.

Received 27 September 1995

Revised version accepted for publication 10 January 1996
In 1959 Ivemark et $a l^{1}$ described a syndrome of renal-hepatic-pancreatic dysplasia in two sibs. No other cases were reported during the next 19 years. In 1978, Crawford ${ }^{2}$ described a similar syndrome in two sibs, one of whom had splenic agenesis and cardiac transposition. Shortly thereafter, Strayer et $a l^{3}$ published a sporadic case and Bernstein et $\mathrm{l}^{4}$ reviewed this syndrome in 1987 and reported five unrelated cases of renal-hepatic-pancreatic dysplasia. ${ }^{34}$ Lastly, Carles et aP in 1988 reported another sporadic case, with clinical features almost identical to the other described cases. We have studied two brothers affected by this syndrome and we suggest an autosomal recessive pattern of inheritance.

\section{Case report}

CASE 1

A male infant was born at 37 weeks of gestation and died $4 \frac{1}{2}$ hours after birth. The mother was a 29 year old woman with a previous history earlier. The pregnancy was complicated by oligohydramnios. The newborn weighed $2800 \mathrm{~g}$ and length was $32 \mathrm{~cm}$. Externally he showed of spontaneous abortion at 3 months, two years
Potter's facies and mild scrotal oedema. Examination of the internal organs showed that both kidneys were enlarged and cystic and the weight of both was $68 \mathrm{~g}$ (normal weight $32 \mathrm{~g}$ ). Neither pelvis nor calyces could be identified. There was agenesis of both ureters and the bladder. The liver was slightly enlarged, weighing $198 \mathrm{~g}$ (normal weight $127 \mathrm{~g}$ ) and showed scarce, small cysts of $0.5 \mathrm{~cm}$ in diameter. Both lungs were hypoplastic and weighed $22 \mathrm{~g}$ (normal weight $48 \mathrm{~g}$ ). The spleen weighed $7 \mathrm{~g}$ and in the splenic hilium there were four accessory spleens of $0.5 \mathrm{~cm}$ in diameter. The brain, spinal cord, and the pancreas appeared normal.

Histological study of the kidneys showed severe distortion of the normal architecture by the presence of numerous dilated ducts lined by cuboidal or flattened epithelium (fig 1). There were primitive duct structures surrounded by collars of mesenchymal connective tissue. Scattered fetal glomeruli were seen. The liver showed microscopically irregular, expanded portal tracts in a varying amount of mature connective tissue and the presence of dysgenetic bile ducts, some of them dilated (fig 2).

\section{CASE 2}

A third pregnancy, one year later, was complicated by oligohydramnios which was detected at week 23 . On sonography performed at that time, enlarged and cystic kidneys were detected, as well as a hepatic cyst. The rest of the fetal structures were of normal appearance. The infant was born at 34 weeks of gestation

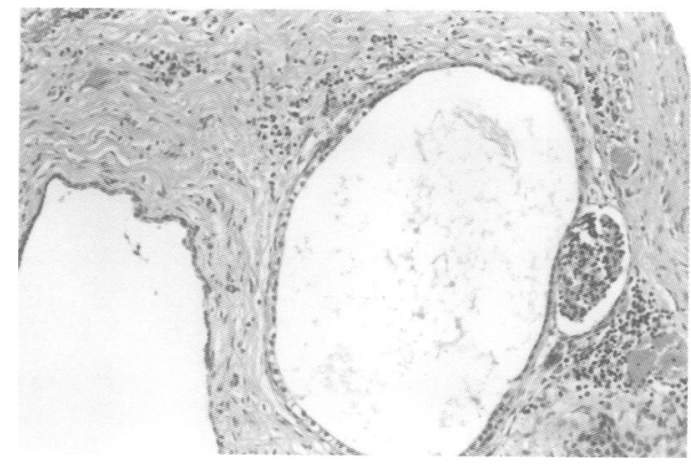

Figure 1 Case 1, microphotography of the kidney showing cysts lined by cuboidal and flattened epithelium and presence of scarce fetal glomeruli (on the right) (HE). 


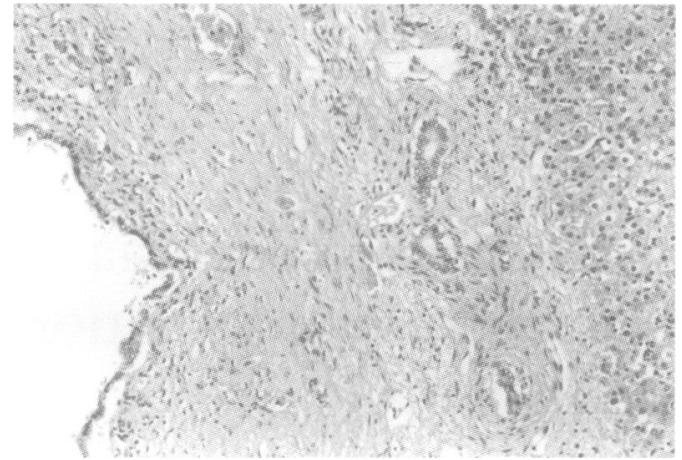

Figure 2 Case 1, microphotography of the liver showing enlarged portal tracts with fibrotic changes and dysgenetic bile ducts, some of them dilated (on the left) (HE).

and died two hours after birth. This second newborn weighed $2600 \mathrm{~g}$ and his length was $27 \mathrm{~cm}$. He also had Potter's facies. The dissection of the organs showed both kidneys to be normal in weight ( $25 \mathrm{~g}$ together), but both were cystic. Renal pelvis and ureters were not seen, but the urinary bladder was present. The pancreas was enlarged, weighing $10 \mathrm{~g}$ (normal weight $3 \mathrm{~g}$ ), and was macroscopically cystic: multiple cysts of $0.8 \mathrm{~cm}$ in diameter were seen. Both lungs were slightly reduced in weight, the weight of both being $30 \mathrm{~g}$.

Both kidneys showed similar histological characteristics to those observed in his brother, with multiple cysts lined by cuboidal or flattened epithelium. Also primitive duct structures and scarce glomeruli were found. The pancreas showed dilated ducts with periductal fibrosis. There was extensive loss of exocrine and endocrine tissue (fig 3).

The parents were screened by ultrasound for abnormalities in the kidneys, liver, or pancreas, but both examinations were normal. They were also asked for any family history of renal, hepatic, or pancreatic disturbances or any hereditary disease with a negative result. No clear history of consanguinity was known in the family, but the fathers of both parents were born in the same small and isolated village in Andalucia (southern Spain). The karyotypes of both parents and the two affected children were normal.

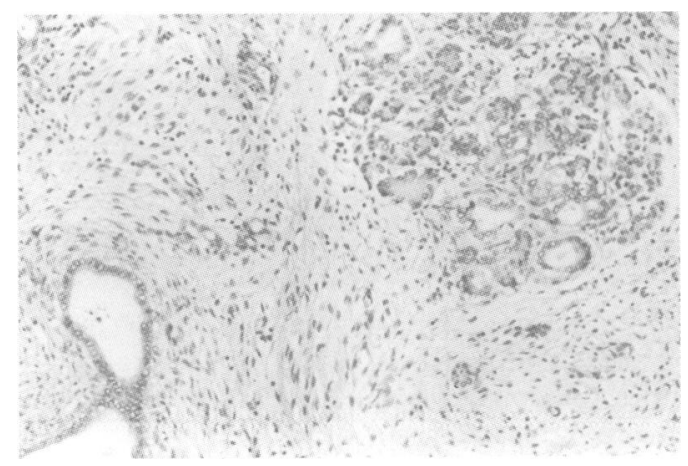

Figure 3 Case 2. Alteration of the pancreatic parenchyma, with ductal dilatation, pericystic fibrosis, and loss of exocrine and endocrine tissues (HE).

\section{Discussion}

Polycystic kidneys are found in a variety of congenital and sporadic syndromes. Potter ${ }^{6}$ discussed polycystic renal disease in a series of classical articles on polycystic kidneys and on the development of human kidneys. According to his classification polycystic kidneys can be of four types. Type I corresponds to what we call nowadays autosomal recessive polycystic kidney disease and is characterised by ectasic collecting tubules. Type II, also termed dysplastic kidney, is characterised by cystic and primitive ducts surrounded by collars of immature fibrous tissue, occasionally containing cartilage. This type may be unilateral as well as bilateral. Although some autosomal recessive cases have been reported, this type of polycystic kidney usually occurs sporadically in the population. Type III corresponds to autosomal dominant polycystic kidney disease and is histologically characterised by the presence of cysts at any point in the nephron. This type of polycystic kidney disease, as well as the recessive type, is bilateral. Type IV is associated with obstruction in the lower urinary tract, but is otherwise indistinguishable from dysplastic kidney type II.

Types I and III constitute the principal monogenic disorders with polycystic kidneys as opposed to types II and IV which are usually sporadic dysplastic kidneys. Autosomal recessive polycystic kidney disease is a genetically homogeneous disorder caused by mutations in a gene localised on chromosome $6 \mathrm{p} 21.1-\mathrm{p} 12 .{ }^{7}$ Although there is a broad range of phenotypes for this entity among different families, the studies performed in children with mild renal disease $^{7}$ and in children with the severe perinatal phenotype ${ }^{8}$ both showed linkage to 6p21.1-p12. This evidence provides essential data for both cloning the gene and for DNA based prenatal analyses in at risk pregnancies. On the other hand autosomal dominant polycystic kidney disease is genetically heterogeneous and is caused by at least three different genes located on chromosomes 16p13.3 (PKD1), ${ }^{9} 4 \mathrm{q} 13-\mathrm{q} 23$ (PKD2), ${ }^{1011}$ and a third locus which has not yet been identified. ${ }^{12} \mathrm{PKD} 1$ account for 85 to $90 \%$ of the cases of autosomal dominant polycystic kidney disease and is phenotypically more severe than PKD2. ${ }^{1314}$ The PKD1 gene has been identified and partially characterised by the European Polycystic Kidney Disease Consortium. ${ }^{15}$ The PKD1 transcript consists of $14148 \mathrm{bp}$, distributed among 46 exons, spanning $52 \mathrm{~kb}$, and is adjacent to the tuberous sclerosis 2 (TSC2) locus. ${ }^{1617}$ An interesting feature of this gene is that all but $3.5 \mathrm{~kb}$ at the $3^{\prime}$ end of the transcript is encoded by a region repeated several times proximally in the same chromosome. A few mutations have already been found in the nonrepeated sequence ${ }^{1819}$ and large deletions have been described in TSC 2 patients with severe renal cystic disease. ${ }^{20}$ The predicted protein encoded by the PKD1 gene is called polycystin, consists of 4304 amino acids, and is probably located in the cell membrane, ${ }^{16121}$ but its function remains to be elucidated. 
Malformations of the liver, pancreas, and other organs may variously accompany the different kinds of polycystic renal disease. For example, autosomal dominant polycystic kidney disease is associated with cysts in the liver and pancreas, cranial aneurysms, diverticuli in the colon, valvular abnormalities, etc, and autosomal recessive polycystic kidney disease is always associated with hepatic lesions resembling congenital hepatic fibrosis.

The clinical and histological features reported in this case resemble most closely the bilateral renal dysplasia reported by Ivemark et $a l^{1}$ as well as the subsequent reports by Crawfurd, ${ }^{2}$ Strayer and Kissane, ${ }^{3}$ Bernstein et $a l,{ }^{4}$ and Carles et al. ${ }^{5}$ In none of these cases was there any associated malformation suggestive of a polymalformation syndrome other than the renal-hepatic-pancreatic dysplasia. Only in the reports of Ivemark et $a l^{1}$ and Crawfurd et $a l^{2}$ were there more than one sib affected. In our patients, as well as in those reported by Ivemark et al, ${ }^{1}$ the degree of involvement of the same organs varied between sibs. Although this syndrome is rare, it is of primary relevance to know the pattern of inheritance in order to be able to offer genetic counselling as precisely as possible. Since we report the third case of sibs affected by this disorder, we think that an autosomal recessive pattern of inheritance should definitely be considered, and therefore a risk of $25 \%$ recurrence of the syndrome should be given for future pregnancies to parents of an affected child.

A number of syndromes involve varying degrees of renal dysplasia. Probably the best known is Meckel syndrome. ${ }^{22}$ The diagnostic criteria for this syndrome require at least two of the triad of cystic kidneys, occipital meningoencephalocele, and polydactyly, with certain other major features such as cleft palate and microcephaly. In our case the absence of other organs affected, apart from kidneys, liver, pancreas, and spleen, rules out this diagnosis. Other syndromes that present with renal-hepatic-pancreatic dysplasia, together with other deformities, are Goldston syndrome, ${ }^{23-25}$ Zellweger syndrome, ${ }^{26}$ several chondrodysplasias, ${ }^{27} 28$ some chromosome aberrations, such as trisomy 9 and 13, and glutaric aciduria type II. ${ }^{29}$ In most of these syndromes varying degrees of involvement of the central nervous system, eyes, skeleton, genitals, or heart can be detected. Although the necropsy data and the normal karyotype exclude most of these entities we could not rule out the remote possibility of a phenotypic variant and the possibility that these apparently single cases of renal-hepatic-pancreatic dysplasia form part of a genetically heterogeneous group. In which case it would appear that the renal-hepaticpancreatic dysplasia could be a non-specific final common pathway of response of the affected organs to a variety of developmental disturbances caused by mutations in different genes. ${ }^{43031}$ The cases we report here seem to be monogenic and belong therefore to the same category as those initially reported by Ivemark et al. ${ }^{1}$ Although in our cases there were abnormalities of the lower urinary tract, which were not present in those reported by Ivemark et $a l$, it is expected that the abnormal morphogenesis of the kidneys also includes the lower urinary tract, as has been found in other syndromes that include renal-hepatic-pancreatic dysplasia. The presence of multiple spleens recorded in one of our cases has also been reported in this syndrome by Bernstein et al. ${ }^{4}$ Crawfurd described one case of splenic abnormality in this syndrome consistent with splenic agenesis. ${ }^{2}$ This suggests that splenic abnormalities are also part of this syndrome.

To conclude, we would like to highlight the fact that when genetic counselling is requested by a family with a history of a previous child affected with a renal-hepatic-pancreatic dysplasia, autosomal recessive inheritance should be considered. Finally, prenatal ultrasound examination of pregnancies seems appropriate for fetal detection of this syndrome in couples with a previously affected child until the gene responsible for the disorder has been identified.

$\mathrm{R}$ Torra is supported by the Comisió Interministerial de Recerca i Innovació Tecnologica CIRIT (Generalitat de Catalunya, FI/94-9102).

1 Ivemark BI, Oldfelt V, Zetterström R. Familial dysplasia of kidneys, liver and pancreas. A probably genetically determined syndrome. Acta Paediatr Scand 1959;48:1-11.

2 Crawfurd Md'A. Renal dysplasia and asplenia in two sibs. Clin Genet 1978;14:338-44.

3 Strayer DS, Kissane JM. Dysplasia of the kidneys, liver and pancreas: report of a variant of Ivemark's syndrome. Hum Pathol 1979;10:228-34.

4 Bernstein J, Chandra M, Creswell J, et al. Renal-hepaticpancreatic dysplasia: a syndrome reconsidered. Am $\mathcal{f}$ Med pancreatic dysplasia: a synd

5 Carles D, Serville F, Dubecq JP, Gonnet JM. Renal, pancreatic and hepatic dysplasia sequence. Eur f Pediatr 1988; 147:431-2.

6 Potter EL. Normal and abnormal development of the kidney. Chicago: Year Book Medical Publishers, 1972.

7 Zerres K, Muecher G, Bachner L, et al. Mapping of the gene for autosomal recessive polycystic kidney disease (ARPKD) to chromosome 6p21-cen. Nature Genet 1994; 7:429-32.

8 Guay-Woodford LM, Muecher G, Hopkins SD, et al. The severe perinatal form of autosomal recessive polycystic kidney disease maps to chromosome 6p21.1-p12: ( 56:1101-7.

9 Reeders ST, Breuning MH, Davies KE, et al. A highly polymorphic DNA marker linked to adult polycystic kidpolymorphic DNA marker linked to adult polycystic kid-

10 Kimberling WJ, Kumar S, Gabow P, Kenyon JB, Conolly CJ, Somlo S. Autosomal dominant polycystic kidney disease: localization of the second gene to chromosome 4q13-q23. Genomics 1993;18:467-72.

11 Peters DJM, Spruit L, Saris JJ, et al. Chromosome 4 localization of a second gene for autosomal dominant polycystic kidney disease. Nature Genet 1993;5:359-62.

12 Daoust MC, Reynolds DM, Bichet DG, Somlo S. Evidence for a third genetic locus for autosomal dominant polycystic kidney disease. Genomics 1995;25:733-6.

13 Parfrey PS, Bear JC, Morgan J, et al. The diagnosis and prognosis of autosomal dominant polycystic kidney disprognosis of autosomal dominant polycys

14 Ravine D, Walker RG, Gibson RN, et al. Phenotype and genotype heterogeneity in autosomal dominant polycystic kidney disease Lancet 1992:340:1330-3.

15 European Polycystic Kidney Disease Consortium. The polycystic kidney disease 1 gene encodes a $14 \mathrm{~kb}$ transcript and lies within a duplicated region on chromosome 16 . Cell 1994;77:281-314.

16 American ADPKD1 Consortium. Analysis of the genomic sequence for the autosomal dominant polycystic kidney disease (PKD1) gene predicts the presence of a leucinerich repeat. Hum Molec Genet 1995;4:575-82.

17 International ADPKD Consortium. Polycystic kidney disease: the complete structure of the PKD1 gene and its protein. Cell 1995;81:289-94.

18 Peral B, Gamble V, San Millán JL, et al. Splicing mutations of the polycystic kidney disease 1 (PKD1) gene induced by intronic deletion. Hum Molec Genet 1995:4:569-74.

19 Turco AE, Rossetti S, Bresin E, Corra S, Gammaro L, Maschio G, Pignatti PF. A novel nonsense mutation in Maschio G, Pignatti PF. A novel nonsense mutation in
the PKD1 gene (C3817T) is associated with autosomal dominant polycystic kidney disease (ADPKD) in a large three-generation Italian family. Hum Molec Genet 1995;4: $1331-5$. 
20 Brook-Carter P, Peral B, Ward CJ, et al. Deletion of the TSC2 and PKD1 genes associated with severe infantile polycystic kidney disease - a contiguous syndrome. Nature Genet 1994;8:332.

21 Hughes J, Ward CJ, Peral B, et al. The polycystic kidney disease 1 (PKD1) gene encodes a novel protein with multiple cell recognition domains. Nature Genet 1995;10: multiple

22 Hsia YE, Bratu M, Herbordt A. Genetics of the Meckel syndrome (dysencephalia splanchnocystica). Pediatrics $1971: 48: 237-47$

23 Goldston AS, Burke EC, D'Agostino A, McCaughey WTE. Neonatal polycystic kidney with brain defect. Am $\mathcal{F}$ Dis Child 1963;106:96-100.

24 Leclerc JP, Canet J, Lancret P, et al. Polykystose hepatopancreat-epididymo-renale et polydystrophie thoracique neo-natales. Arch Fr Pediatr 1971;28:425-34

25 Gloeb DJ, Valdes-Dapena MV, Salman F, O'Sullivan MJ, Quetel TA. The Goldston syndrome: report of a case. Pediatr Pathol 1989;9:337-43.
26 Bowen P, Lee CSN, Zellweger H, Lindenberg R. A familial syndrome of multiple congenital defects. Bull fohns Hopkins Hosp 1964;114:402-14.

27 Jeune M, Beraud C, Carron R. Dystrophie thoracique as phyxiante de caractère familial. Arch Fr Pediatr 1955;12 886-91.

28 Saldino RM, Noonan CD. Severe thoracic dystrophy with striking micromelia, abnormal osseous development, instriking micromelia, abnormal osseous deveral abnormalities. cluding the spine, and
$A 7 R$ 1972;114:257-63.

29 Goodman SI, Markey SP, Moe PG, Miles BS, Teng CC. Glutaric aciduria; "new" disorder of amino acid metabolism. Biochem Med 1975;12:12-21.

30 Hunter AGW, Jimenez C, Tagawi FRG. Familial renalhepatic-pancreatic dysplasia and Dandy-Walker cyst: a hepatic-pancreatic dys 7 Med Genet 1991;41:201-7.

31 Kudo M, Tamura K, Fuse Y. Cystic dysplastic kidneys associated with Dandy-Walker malformation and congenital hepatic fibrosis. Am $\mathcal{F}$ Clin Pathol 1985;84:459-63. 